\title{
Field scale variability of soil structure and its impact on crop growth and nitrate leaching in the analysis of fertilizing scenarios
}

\author{
P.A. Finke \\ Department of Soil Science and Geology, P.O. Box 37, 6700 AA Wageningen, The Netherlands
}

(Received September 24, 1992; accepted after revision November 11, 1992)

\section{ABSTRACT}

Soil structure variability was inventoried on a field scale, and translated to basic input data for a solute transport and crop production simulation model. After validation of the model, it was used to simulate the spatially varying effect of slurry application and $\mathrm{N}$-fertilizing scenarios by multiple pointsimulations. Feasibility of scenarios was determined by comparing nitrate leaching concentrations with current and pursued threshold levels. Disjunctive kriging was used to estimate and map the probability that these threshold levels were exceeded.

Emphasis was given to the effect of soil-specific slurry application rates and $\mathrm{N}$-fertilizer levels on leaching probabilities and crop yields. Soil-specific $\mathrm{N}$-treatments increased field yields, because crop response to $\mathrm{N}$, both in slurry and in fertilizer, was soil dependent. The leaching response to $\mathrm{N}$-treatment was also soil dependent.

\section{INTRODUCTION}

Currently, legislation is being developed in the Netherlands to restrict inputs into the environment of polluting substances. Agriculture has been identified as a possible source of (e.g.) biocides, nitrates and ammonia. In order to make effective laws, possible effects of protective measures have to be evaluated by scenario analyses. In agricultural practice, management takes place on a field scale at farm level, and since the management can be influenced by legislation, scenario analyses should be carried out on the same field scale. Management scenarios can be analyzed by using simulation models. Input data should reflect field variability. This enables the evaluation of not only the average result of implementing a measure, but also its field scale variability. Knowledge about this variability allows the effect of an implemented measure to be expressed in terms of a probability distribution. Such a distribution can be used to estimate the probability that the effect of a measure is

\footnotetext{
'Present address: Winand Staring Centre, P.O. Box 125, 6700 AC Wageningen, The Netherlands.
} 
violating a statutory threshold value. Spatial variability of a variable can be translated into probability density functions by using the spatial prediction method disjunctive kriging.

This paper describes two scenario-analyses that were made to optimize the addition of organic manure and of inorganic fertilizer on a field scale with respect to nitrogen losses to atmosphere and groundwater. Special emphasis was given to the effect these additions would have on crop production. Both scenarios that were analyzed explicitly used soil structure variability to generate the dynamic soil physical characteristics water retention and hydraulic conductivity, and the static characteristics bulk density, texture and organic matter content. These characteristics were necessary to describe field scale variability of water flow and nitrogen fate by using a simulation model.

\section{MATERIALS AND METHODS}

\section{Spatial variability of soil structure}

The area under study is an agricultural field in the Wieringermeer polder in the northwestern part of the Netherlands. Soils were classified as fine-loamy, calcareous, mesic Typic Udifluvents (Soil Survey Staff, 1975) and show a highly variable soil structure. Soil structure variability was caused by the complex sedimentation history of the area, which was part of a mud-flat landscape of tidal channels separating shoals before it was reclaimed.

A problem encountered when the behaviour of these stratified soils is to be simulated, is how to discretize the soil profile. Obviously, the thin layers visible in a vertical section (Fig. 1) cannot be analyzed separately for the determination of soil physical characteristics, and cannot be recognized from auger-cores in a soil survey. However, vertical successions of these thin layers can be recognized by their over-all structure and can be analyzed. A study was dedicated to whether these generalised layers could serve as functional layers.

A functional layer is a layer that has functional hydrological properties significantly different from those of other functional layers, and has a low internal variability (Wösten et al., 1990; Finke et al., 1992). Functional properties used were (Wösten et al., 1986):

(1) the travel time during a period of steady infiltration, and

(2) the maximal height above the water table at which a defined upward flux can be maintained.

For the study area, Finke and Bosma (1993) concluded that soil profiles could successfully be generalized into a vertical sequence of three different functional layers, which were easily recognizable in a regular soil survey. The properties of different functional layers proved to be significantly different, and using the functional layers to generate input for a simulation model on a number of test plots resulted in accurate simulations. 


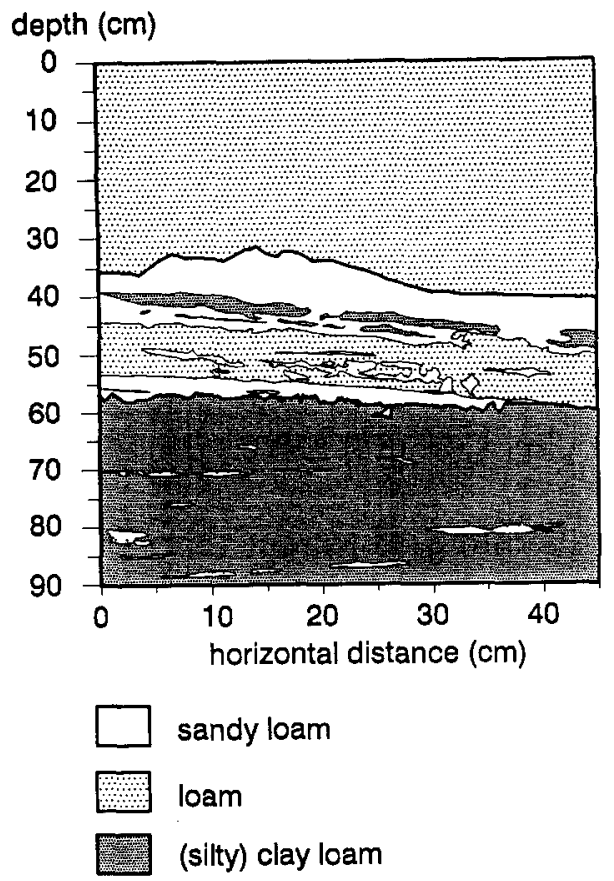

log-conductivity (cm/day)

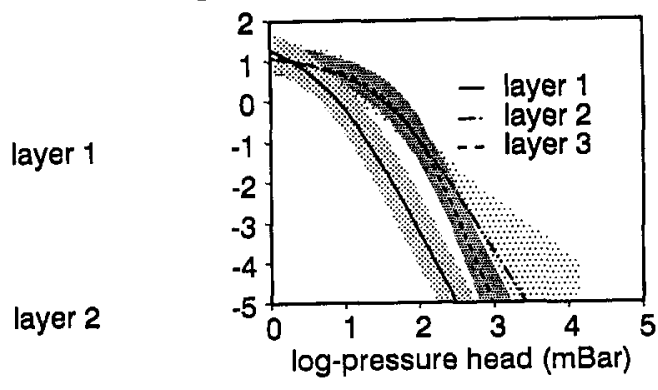

layer 3

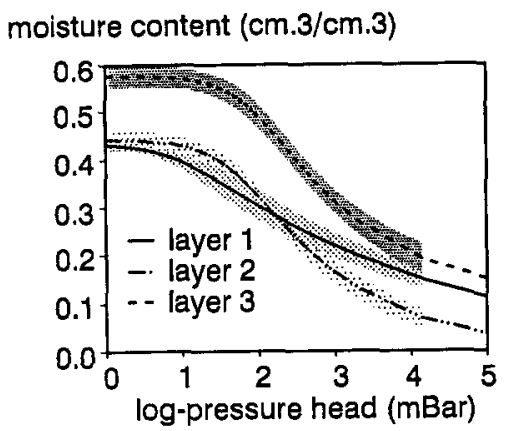

Fig. 1. Vertical section showing the thinly stratified soil profile and its generalization into three functional layers.

The problem of inventorying spatial variability of soil structure was thus reduced to mapping the thickness and depth of functional layers. A two-phase soil survey was made. In the first phase, a nested sampling scheme was followed (Webster, 1977) during which 93 profile descriptions were collected with the purpose to quantify variability at both short and longer ranges relative to the field scale. Based on variogram analysis and interpretation of aerial photographs it was decided to sample a triangular grid with a mesh of $16 \mathrm{~m}$ in the second phase of the soil survey (Finke, 1991). The resulting 402 profile descriptions that were collected, were used to produce a soil map (Fig. 2), and were translated into as many location-specific input files for computersimulations.

\section{Model description}

To perform the scenario analyses, an existing model (LEACHM, Hutson and Wagenet, 1991) was extended with a potato crop growth submodel. The model simulates water flow, nitrogen transformations and nitrogen transport and 
distance (m)

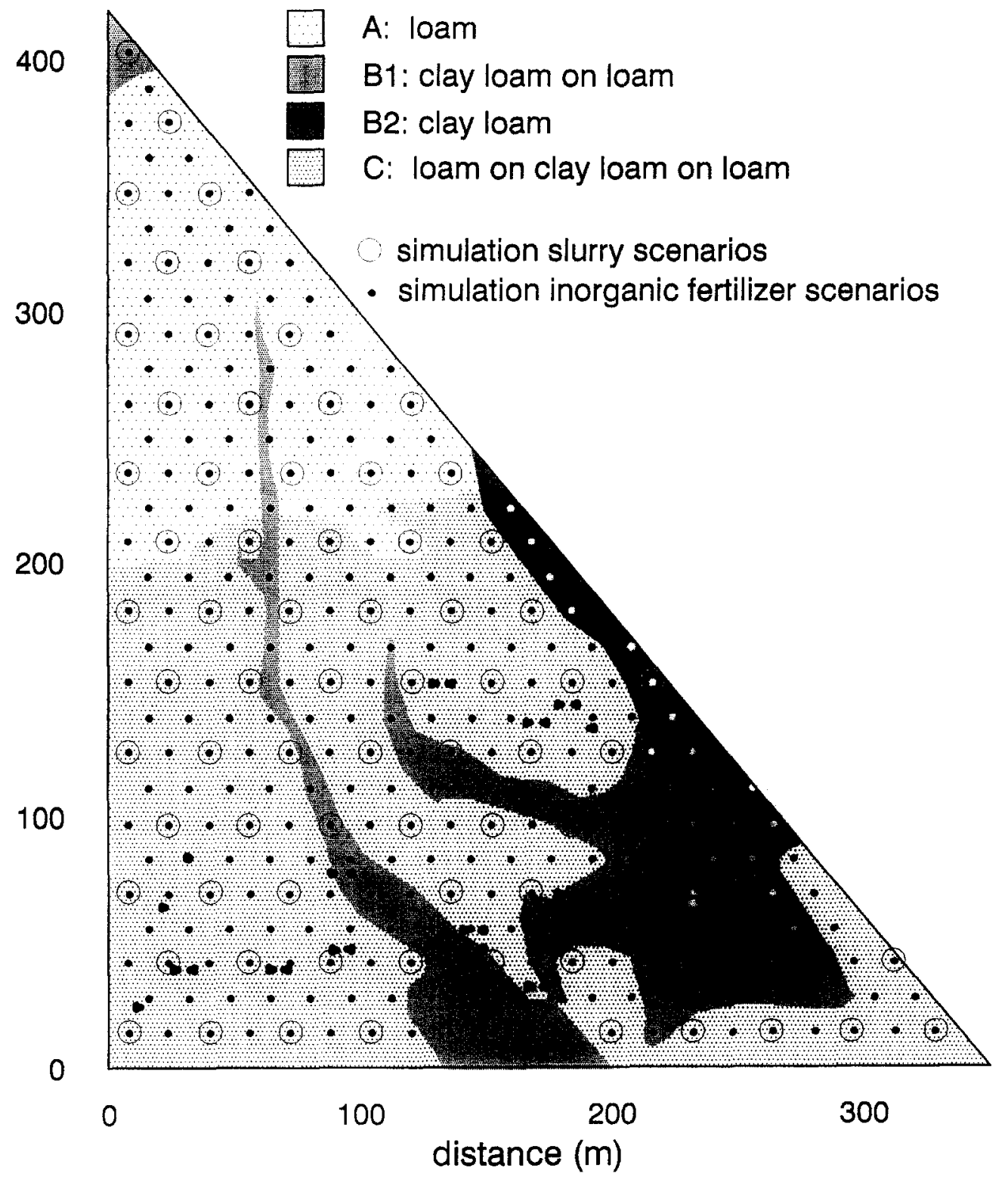

Fig. 2. Soil map and simulation locations used in the scenario analyses. 
potato crop growth. The water flow is calculated using a finite-difference solution to the Richard's equation:

$\frac{\partial \theta}{\partial t}=\left(\frac{\partial}{\partial}\right)\left(K(\theta) \frac{\partial H}{\partial z}\right) U(z, t)$

where $\theta$ is the volumetric water content $\left(\mathrm{m}^{3} / \mathrm{m}^{3}\right), t$ is the time (days), $H$ is the hydraulic head $(100 \times \mathrm{Pa})$, defined as $H=h-z$, where $h$ is the soil matric potential and $z$ is the depth in $\mathrm{cm}, K$ is the hydraulic conductivity $(\mathrm{cm} /$ day) and $U$ is a sink term representing water lost by transpiration $(\mathrm{cm})$. The daily potential transpiration was calculated by (Belmans et al., 1983):

$T_{\mathrm{p}}=E T_{\mathrm{p}} \cdot[1-\exp (-0.6 I)]$

where $T_{\mathrm{p}}$ is the potential transpiration (cm/day), $E T_{\mathrm{p}}$ is the potential evapotranspiration ( $\mathrm{cm} /$ day) and $I$ is the leaf area index $\left(\mathrm{m}^{2} / \mathrm{m}^{2}\right)$. The functions between $K, \theta$ and $h$ that are required, were described using the closed form equations by Van Genuchten (1980).

The performance of the water flow submodel, using functional layers to generate the hydraulic characteristics, was tested by comparison of measured and simulated matric potentials on five plots at three depths (Finke, 1992; Finke and Bosma, 1993).

Nitrogen cycling is described according to the concepts and equations of Johnsson et al. (1987). Three organic nitrogen pools, characterized as a quickly degrading manure and litter pool and a relatively stable humus pool, are distinguished in the model. Also a urea pool and mineral ammonia and nitrate pools are identified. Mineralization processes, volatilization, nitrification and denitrification are described by first-order rate constants, volatilization occurring only from the surface layer. Rate constants are adjusted for temperature and water content effects (Johnsson et al., 1987). Ammonium, nitrate and urea can be partially sorbed onto soil surfaces through a linear sorption isotherm. Chemical transport is simulated by a numerical solution to the convection-dispersion equation (Wagenet, 1983):

$\frac{\partial(\theta c)}{\partial t}+\frac{\partial(\rho S)}{\partial t}=\frac{\partial}{\partial z}\left(\theta D(\theta, q) \frac{\partial c}{\partial z}-q c\right)-U(z, t) \pm \phi(z, t)$

where $c$ is the chemical concentration in the liquid phase $\left(\mathrm{mg} / \mathrm{dm}^{3}\right), s$ is the chemical concentration in the sorbed phase $(\mathrm{mg} / \mathrm{kg}$ dry soil $), \rho$ is the soil bulk density $\left(\mathrm{kg} / \mathrm{dm}^{3}\right), D(\theta, q)$ is the effective dispersion coefficient $\left(\mathrm{mm}^{2} /\right.$ day), $q$ is the water flux density (mm/day), $\phi$ is a source/sink term (mg/ $\mathrm{dm}^{3}$, day) representing gains/losses through transformation and $U(z, t)$ is the plant uptake of nitrogen $\left(\mathrm{mg} / \mathrm{dm}^{3}\right.$,day). The plant uptake of nitrogen is determined by the transpiration flux and concentrations in the compartments 
of the rooted zone. For a extensive description of LEACHN, reference is made to Hutson and Wagenet (1991).

The performance of the nitrogen submodel was tested by comparing measured and simulated mineral nitrogen of the upper profile meter on 8 plots receiving various fertilizer and organic manure treatments (Finke, 1992).

The potato crop biomass production is schematized in Fig. 3. The water stressed dry matter growth rate as a result of the actual transpiration rate is calculated according to Feddes et al. (1988):

$q_{\mathrm{w}}=0.5\left\{W \frac{T}{\Delta e}+q_{\mathrm{m}}-\left[\left(q_{\mathrm{m}}+W \frac{T}{\Delta e}\right)^{2}-4 q_{\mathrm{m}} W \frac{T}{\Delta e}(1-\xi)\right]^{1 / 2}\right\}$

In this equation, $q_{\mathrm{m}}$ is the maximum dry matter growth rate (depending upon latitude, global radiation, the leaf area index and the maintenance respiration $), q_{\mathrm{w}}$ is water stressed dry matter growth rate $\left(\mathrm{kg} \mathrm{ha}^{-1}\right.$ day $\left.^{-1}\right), W$ is the maximum water use efficiency $\left(\mathrm{kg} \cdot \mathrm{mbar} \mathrm{ha}^{-1} \mathrm{~mm}^{-1}\right), T$ is the actual transpiration ( $\mathrm{mm} /$ day), $\Delta e$ is the average vapour pressure deficit of the air ( $m b a r)$ and $\xi$ is a mathematical curve fitting parameter.

Furthermore, the growth rate stressed by a limiting nitrogen availability is simulated by multiplication of the water stressed growth rate $q_{\mathrm{w}}$ by a stress factor $S_{n}$, calculated from (Greenwood et al., 1985; Neeteson et al., 1987):

\section{GLOBAL RADIATION}

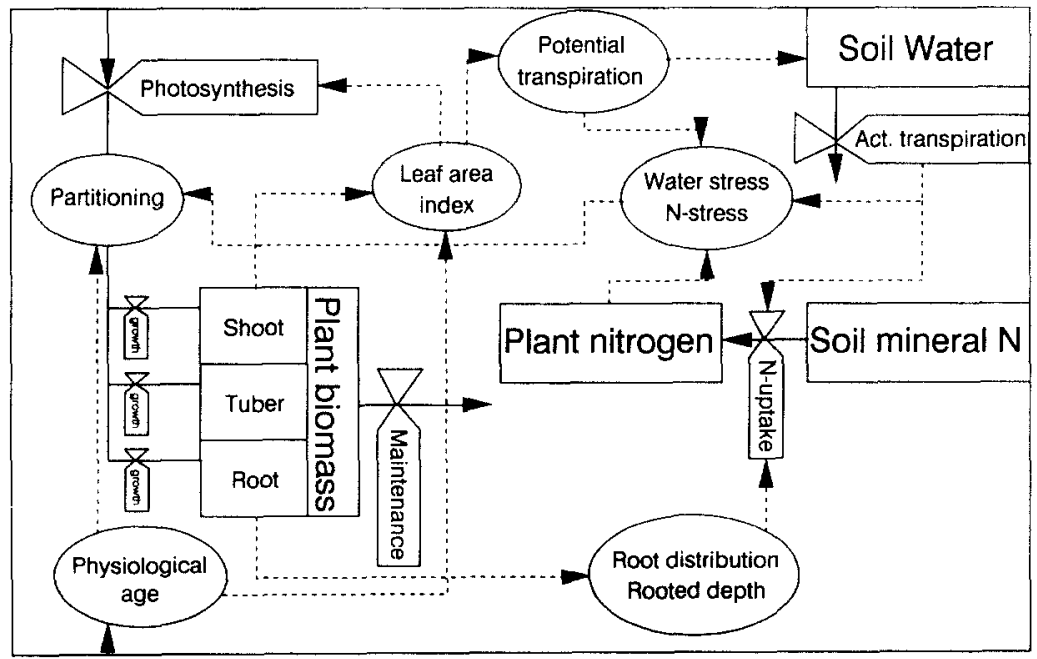

AIR TEMPERATURE

Fig. 3. Processes simulated in the potato growth submodel. Boxes indicate pools, valves indicate processes, ellipses indicate auxiliary variables or processes, solid lines indicate mass or energy transport and dashed lines indicate information flows. 
$S_{n}=\min \left[1, \frac{P_{\mathrm{W}}-P_{0}}{P_{\mathrm{M}}-P_{0}}\right]$

where $S_{n}$ is the stress factor for the current day, $P_{\mathrm{W}}$ is the actual $\% \mathrm{~N}$ in total dry matter, $P_{0}$ is the $\% \mathrm{~N}$ in total dry matter when growth ceases and $P_{\mathrm{M}}$ is the minimum \% $\mathrm{N}$ in total dry matter to have the maximum growth rate.

The plant physiological age, characterized by the temperature-sum since the day of emergence, is used to partition the biomass increase to shoots, tubers and roots. Occurrence of stress due to limited nitrogen and/or water availability will cause the partitioning to be changed in favour of root growth and disfavour of shoot and tuber biomass growth. The leaf area index (LAI) is considered to be a linear function of the shoot biomass until a certain temperature-sum is reached, whereafter the LAI becomes a monotonically decreasing function of the temperature-sum and the shoot biomass according to:

$I=\left\{\begin{array}{l}a B^{*}{ }_{T} \\ a B_{T}\left(1-\frac{\left.\sum_{\text {day =emergence }}^{\sum_{\text {current }}^{\text {current }}}\left(T_{\text {day }}-b\right)+c\right)}{\left.\sum_{\text {day }=\text { emergence }}-b\right)}\right)\end{array}\right.$

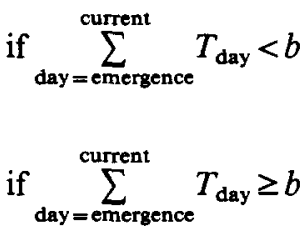

where $a$ is a coefficient ( $\mathrm{ha} / \mathrm{kg}), b$ is the critical temperature-sum $\left({ }^{\circ} \mathrm{C}\right), T$ is the average temperature for the current day $\left({ }^{\circ} \mathrm{C}\right)$ and $c$ is a constant $\left({ }^{\circ} \mathrm{C}\right)$.

The performance of the potato crop growth model was tested by comparison of measured (through remote sensing) and simulated leaf area indexes, and by comparison of measured versus simulated final tuber yields.

\section{Fertilizer scenarios}

In conventional agriculture in the Netherlands, nitrogen fertilizer additions are high. In areas with factory-farming, organic manure applications are reported to cause leaching of nitrates to the groundwater. Legislation is being implemented to minimize leaching hazards. To evaluate the effects on nitrate leaching of different levels of manure application and of inorganic fertilizer, two scenarios were investigated.

The first scenario was investigated to optimize organic manure additions with respect to ammonia volatilization, nitrate leaching and potato tuber yield levels. The simulation period comprised a period of 17 months, from April 1, 1989 to September 1, 1990. In this period 3 crops were grown: spring barley, followed by a catchcrop (ryegrass) in the same year and by potatoes in the next spring. A surface application of chicken slurry was compared with an 
incorporation in the upper $15 \mathrm{~cm}$. The application date was fixed the day after the harvest of the barley crop in August. Both simulations focused on a representative profile for each one of the four soil types present in the field. The best type of application, leading to the smallest loss of $\mathrm{N}$ by volatilization and leaching, was thereafter optimized by stepwise adjusting the amount of applied manure until a critical leaching concentration (at $80 \mathrm{~cm}$ depth) would not be exceeded over the year following the application. Each optimization step comprised a series of 82 simulations, spatially distributed following a triangular grid with a mesh of $32 \mathrm{~m}$ (Fig. 1).

The second scenario evaluated 6 variants of inorganic fertilizer application. The variants were based on the fertilizer advice obtained from:

$N_{\mathrm{adv}}=N_{\mathrm{opt}}-a N_{\min }$

where $N_{\text {adv }}$ is the advice, $N_{\text {opt }}$ is the optimal amount of nitrogen in the rootable zone before planting (evaluated from national trials), $a$ is a crop-dependent factor and $N_{\min }$ is the amount of inorganic nitrogen present in the rootable zone before fertilizing. Variants 1 to 5 comprised modifications of the real $N_{\text {adv }}$ by factors of $0.25,0.50,1.00,1.50$ and 2.00 respectively, and variant 6 modified $N_{\text {opt }}$ by a factor of 2 (Table 1 ).

Nitrate leaching concentrations in the hydrological year between April 1, 1989 and April 1, 1990 were simulated. These loadings were compared with the current ( $50 \mathrm{mg}$ nitrate $/ \mathrm{dm}^{3}$ ) and with the pursued ( $25 \mathrm{mg}$ nitrate $/ \mathrm{dm}^{3}$ ) critical concentration levels in leaching water in the Netherlands. Potato dry matter yields were simulated to evaluate the effect of changed fertilizing levels on crop production.

\section{TABLE 1}

Description of scenarios analyzed. $B$ and $P$ are regular Dutch fertilizer advice levels for barley and potatoes respectivily, where $B=110-N$ and $P=285-1.1 \mathrm{~N}$. b, $c$ and $p$ are actual fertilizer gifts for barley, catchcrop and potatoes. $N$ is the amount of mineral nitrogen $(\mathrm{kg} / \mathrm{ha})$ in layer $0-60 \mathrm{~cm}$ before planting

\begin{tabular}{llllll}
\hline Scenario & Variant & $\begin{array}{l}\text { No. of } \\
\text { simulations }\end{array}$ & $\begin{array}{l}\text { Amount given } \\
\text { (kg N/ha) }\end{array}$ & \\
\hline Chicken slurry & 1: surface appl. & 4 & 300 & \\
& 2: incorp. 0-15 cm & 4 & 300 & & \\
& 3: optimization & 82 & $250-500$ & & \\
Inorganic N & 0: initializing run & 402 & $b=\mathrm{B}$ & $\mathrm{c}=60$ & $\mathrm{p}=\mathrm{P}$ \\
& 1: advice-75\% & 402 & $\mathrm{~b}=0.25 \mathrm{~B}$ & $\mathrm{c}=15$ & $\mathrm{p}=0.25 \mathrm{P}$ \\
& 2: advice-50\% & 402 & $\mathrm{~b}=0.50 \mathrm{~B}$ & $\mathrm{c}=30$ & $\mathrm{p}=0.50 \mathrm{P}$ \\
& 3: conform advice & 402 & $\mathrm{~b}=\mathrm{B}$ & $\mathrm{c}=60$ & $\mathrm{p}=\mathrm{P}$ \\
& 4: advice+50\% & 402 & $\mathrm{~b}=1.50 \mathrm{~B}$ & $\mathrm{c}=90$ & $\mathrm{p}=1.50 \mathrm{P}$ \\
& 5: advice+100\% & 402 & $\mathrm{~b}=2.00 \mathrm{~B}$ & $\mathrm{c}=120$ & $\mathrm{p}=2.00 \mathrm{P}$ \\
& 6: optimal N+100\% & 402 & $\mathrm{~b}=220-\mathrm{N}$ & $\mathrm{c}=120$ & $\mathrm{p}=570-1.1 \mathrm{~N}$ \\
\hline
\end{tabular}


Simulations started with 2 years of fertilizing according to the current advice (variant 0 in Table 1 ), with initial nitrogen amounts corresponding to the level observed in the field. Thereafter, variants 1 to 6 were simulated, each with an initial nitrogen amount that would be present after two years of standard fertilization. This was done to avoid lagged effects of the current high fertilizer levels on low input scenarios. Next, a period of 17 months was simulated, assuming the same cropping sequence as in the slurry scenarios. All variants were simulated at 402 locations (Fig. 1).

After simulating the effect of varying fertilizer levels, the effect of varying the spatial resolution of application was also investigated. For variants 0 to 3 , three methods were compared, different in the way fertilizing advices are obtained, using eq. (7):

(1) the advice is based on point-specific N-status;

(2) the advice is based on the average $\mathrm{N}$-status for the soil unit;

(3) the advice is based on the field-average $\mathrm{N}$-status.

Method (3) follows traditional agricultural practice, method (2) uses available soil survey information and method (1) reflects the maximum attainable spatial precision.

Inputs into the simulation model that varied according to spatial variability observed in the field, were:

(1) thickness and texture of each functional layer: by location;

(2) hydraulic characteristics, bulk density and organic matter content: by functional layer;

(3) depth of groundwater in time: translated from a monitoring series from the same field to other locations by surface topography.

Inputs into the simulation model that were not assumed to vary over the field were:

(1) initial nitrogen amounts and depth distribution;

(2) precipitation, air temperature and potential evapotranspiration;

(3) nitrogen transformation rate constants (though correction for temperature and water content may cause variability in actual rate factors).

\section{Disjunctive kriging}

The simulations were aimed at minimizing the risk that nitrate loadings into the groundwater would exceed a critical value of $50 \mathrm{mg}$ nitrate $/ \mathrm{dm}^{3}$. It is intuitively clear, that when this risk is to be estimated at locations where no value is known, it will depend on values obtained in the neighbourhood and on the variability. In areas where measured leaching rates are large, there will be a high probability that predicted leaching rates will be large, as well. In areas where leaching is highly variable, uncertainty leads also to a greater estimated risk. This risk can be evaluated by estimating the probability that the $50 \mathrm{mg}$ nitrate $/ \mathrm{dm}^{3}$ level is exceeded. 
Estimating a probability requires the distribution of the variable "nitrate loading" to be known. Because loadings are concentrations, a skew distribution can be expected, since negative concentrations cannot occur. This may require, that the actual distribution be transformed to a standard normal distribution before probabilities based on the observed data can be calculated. The spatial prediction procedure disjunctive kriging (DK) aims at obtaining an estimator of the conditional probability that a measured variable exceeds a cutoff level at an unvisited location, irrespective of its distribution (Yates et al., 1986; Webster and Oliver, 1989). The probability is conditional, because:

(i) the spatial correlation structure of the variable is taken into account; (ii) the probability is conditioned on a set of observations.

In the application of DK, three assumptions are made:

(i) The original observations $Z(x)$ must be second order stationary; (ii) a function exists that transforms arbitrarily distributed $Z(x)$ to normally distributed $Y(x)$ and that is invertible. This assumption has been proven to be always correct (Kim et al., 1977); (iii) the function produced by the transform $(Y(x))$ has a bivariate normal distribution for each pair of locations.

In DK, a function is sought that is invertible, and that can transform values from whatever distribution to a standard normal distribution. Such a function can be approximated by composing each observation from a number $(K)$ of Hermite polynomials with the appropriate coefficients. The prediction of the variable $Z\left(x_{0}\right)$ on an unvisited point $x_{0}$ is thus expanded to a linear combination of predictions in $x_{0}$ for each one of $K$ Hermite polynomials:

$Z_{\mathrm{DK}}^{*}\left(x_{0}\right)=\sum_{k=0}^{K} C_{k} H_{k}^{*}\left[Y\left(x_{0}\right)\right]$

where the coefficients $C_{k}$ were obtained from the observations by Hermite integration (Abramowitz and Stegun, 1965); and $H_{k}\left[Y\left(x_{0}\right)\right]$, the value for the $k$ th Hermite polynomial of the normalized variable $Y$ on location $x_{0}$, is estimated by weighing Hermite polynomials from the same order at $n$ neighbouring observation points by:

$H_{k}^{*}\left[Y\left(x_{0}\right)\right]=\sum_{i=1}^{n} b_{i k} H_{k}\left[Y\left(x_{i}\right)\right]$

where the weights $b_{i k}$ are determined by solving the system:

$$
\left(\rho_{0 j}\right)^{k}=\sum_{i=1}^{n} b_{i k}\left(\rho_{i j}\right)^{k} \quad j=1,2, \ldots, n
$$

where $\rho_{i j}$ is the autocorrelation between observations $i$ and $j$.

A predictor of the conditional probability of exceeding a cutoff level is evaluated by defining an indicator function $\theta$ : 


$$
\theta_{y_{c}}= \begin{cases}1 & \text { if } Y \geq y_{c} \\ 0 & \text { if } Y<y_{c}\end{cases}
$$

where $y_{\mathrm{c}}$ is the normalized cutoff level (relating to the actual cutoff level $z_{\mathrm{c}}$ ) and $Y$ is the normalized variable (relating to $Z$ ). The conditional probability of $Z\left(x_{0}\right)$ exceeding $z_{\mathrm{c}}$ is estimated by the conditional expectation of the indicator function $\theta_{y c}(Y)$ in location $x_{0}$.

Hereto $\theta_{y c}\left(Y\left(x_{0}\right)\right)$ is expanded to a series of Hermite polynomials, so that the conditional probability is estimated by the sum of the predictions of the Hermite polynomials describing $\theta_{y c}\left(Y\left(x_{0}\right)\right)$ :

$P^{*}\left(x_{0}\right)=1-G\left(y_{\mathrm{c}}\right)+g\left(y_{\mathrm{c}}\right) \sum_{k=1}^{K} H_{k-1}\left(y_{\mathrm{c}}\right) H_{k}^{*}\left[Y\left(x_{0}\right)\right] / k !$

where $H_{k-1}$ is known; and $\left.H_{k}^{*} Y\left(x_{0}\right)\right]$ was estimated during the disjunctive prediction procedure; and $G\left(y_{\mathrm{c}}\right)$ is the cumulative standard normal probability density for $y_{\mathrm{c}}$; and $g\left(y_{\mathrm{c}}\right)$ is the standard normal probability density for $y_{\mathrm{c}}$.

For a detailed description of the DK procedure, reference is made to Yates et al. (1986).

\section{RESULTS AND DISCUSSION}

\section{Model performance}

A comparison between simulated and measured characteristics is given in Fig. 4a-d. Simulated soil matric potentials agreed well with measurements $\left(R^{2}\right.$ of 0.74$)$ when the soil matrix was unsaturated. Near saturation, simulations deviate from measurements, but differences are small. Simulated inorganic nitrogen contents in the upper meter were simulated reasonably well $\left(R^{2}=0.71\right)$, when deviations from measurements (tens of $\mathrm{kg} \mathrm{N} / \mathrm{ha}$ ) are compared to fertilizer levels (hundreds of $\mathrm{kg} \mathrm{N} / \mathrm{ha}$ ).

Simulated leaf area indexes are generally simulated well $\left(R^{2}=0.58\right)$, since most simulated values are found within the $1 \sigma$ confidence zone associated with the remote sensing estimates (Fig. $4 \mathrm{c}$ ). Simulated final potato yields are compared to measurements in Fig. $4 \mathrm{~d}$. The relatively small $R^{2}(0.18)$ is probably caused by variability in the depth distribution of inorganic $\mathrm{N}$ at the start of the growing season, which was unknown and therefore assumed homogeneous (Finke, 1992).

\section{Slurry scenarios}

Simulation results at four soil profiles, each representative for one soil unit, are given in Table 2. In all soil units, a positive response of crop production 
simulated

a

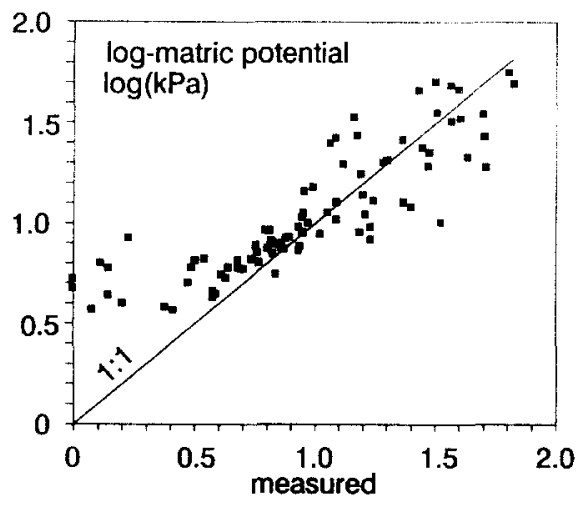

simulated

C

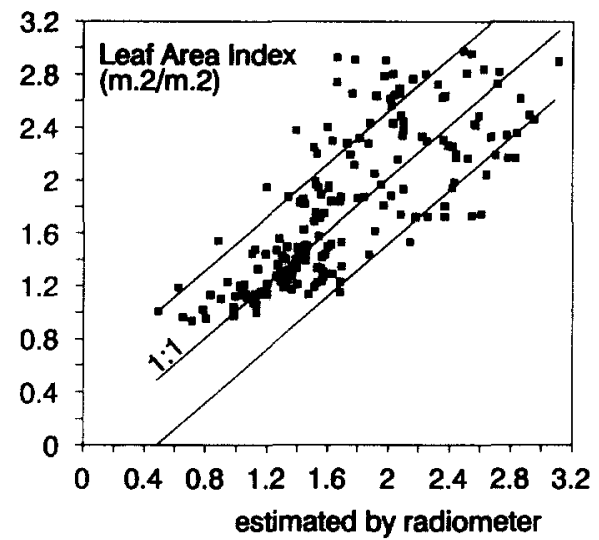

simulated

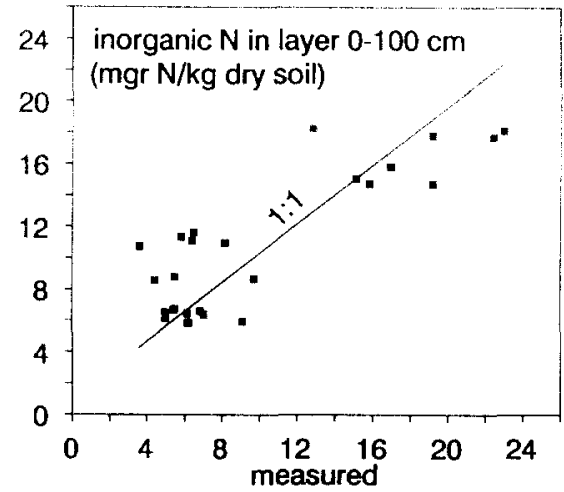

simulated

d

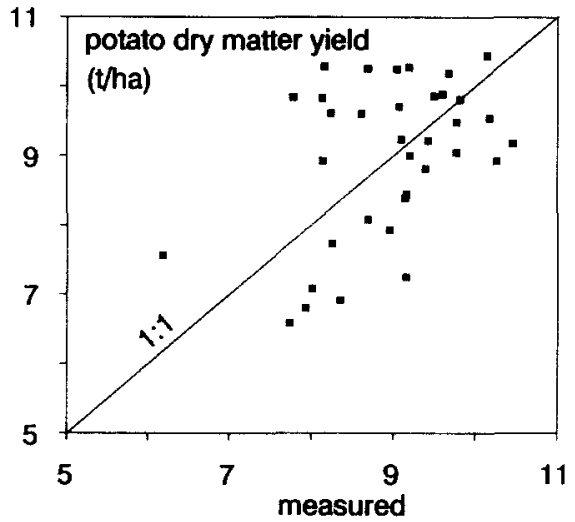

Fig. 4. Simulated and measured characteristics of the water submodel (a), the nitrogen submodel (b) and the potato production submodel for leaf area indexes (c) and final potato yields (d). Two lines parallel to the 1:1 line in (c) indicate one standard deviation confidence zones of the LAI estimated by remote sensing.

\section{TABLE 2}

Simulated nitrogen losses ( 17 months) and dry matter tuber yields in four characteristic soil profiles for surface application (s) and incorporation (i) of $300 \mathrm{~kg} \mathrm{~N} / \mathrm{ha}$ slurry. Soil unit codes refer to Fig. 2

\begin{tabular}{|c|c|c|c|c|c|c|c|c|}
\hline \multirow[t]{2}{*}{$\begin{array}{l}\text { Soil } \\
\text { unit }\end{array}$} & \multicolumn{2}{|c|}{$\begin{array}{l}\mathrm{NH}_{3} \text {-volat. } \\
(\mathrm{kg} \mathrm{N} / \mathrm{ha})\end{array}$} & \multicolumn{2}{|c|}{$\begin{array}{l}\mathrm{NO}_{3} \text {-leaching } \\
(\mathrm{kg} \mathrm{N} / \mathrm{ha})\end{array}$} & \multicolumn{2}{|c|}{$\begin{array}{l}\text { Plant uptake } \\
\text { (kg N/ha) }\end{array}$} & \multicolumn{2}{|c|}{$\begin{array}{l}\text { Yield } \\
(\mathrm{t} / \mathrm{ha})\end{array}$} \\
\hline & $\mathrm{s}$ & $\mathrm{i}$ & $\mathbf{s}$ & $\mathrm{i}$ & $\mathbf{s}$ & i & $\mathbf{s}$ & $\mathrm{i}$ \\
\hline $\begin{array}{l}\text { A } \\
\text { B1 } \\
\text { B2 } \\
\text { C }\end{array}$ & $\begin{array}{l}193.3 \\
193.6 \\
192.6 \\
194.0\end{array}$ & $\begin{array}{l}151.6 \\
151.9 \\
150.9 \\
152.5\end{array}$ & $\begin{array}{l}9.1 \\
6.7 \\
6.9 \\
7.3\end{array}$ & $\begin{array}{l}10.3 \\
7.4 \\
8.0 \\
8.0\end{array}$ & $\begin{array}{l}697.7 \\
657.2 \\
646.1 \\
672.5\end{array}$ & $\begin{array}{l}701.2 \\
679.4 \\
664.4 \\
696.4\end{array}$ & $\begin{array}{l}11.3 \\
10.4 \\
8.7 \\
10.8\end{array}$ & $\begin{array}{l}12.0 \\
12.0 \\
9.5 \\
12.3\end{array}$ \\
\hline
\end{tabular}



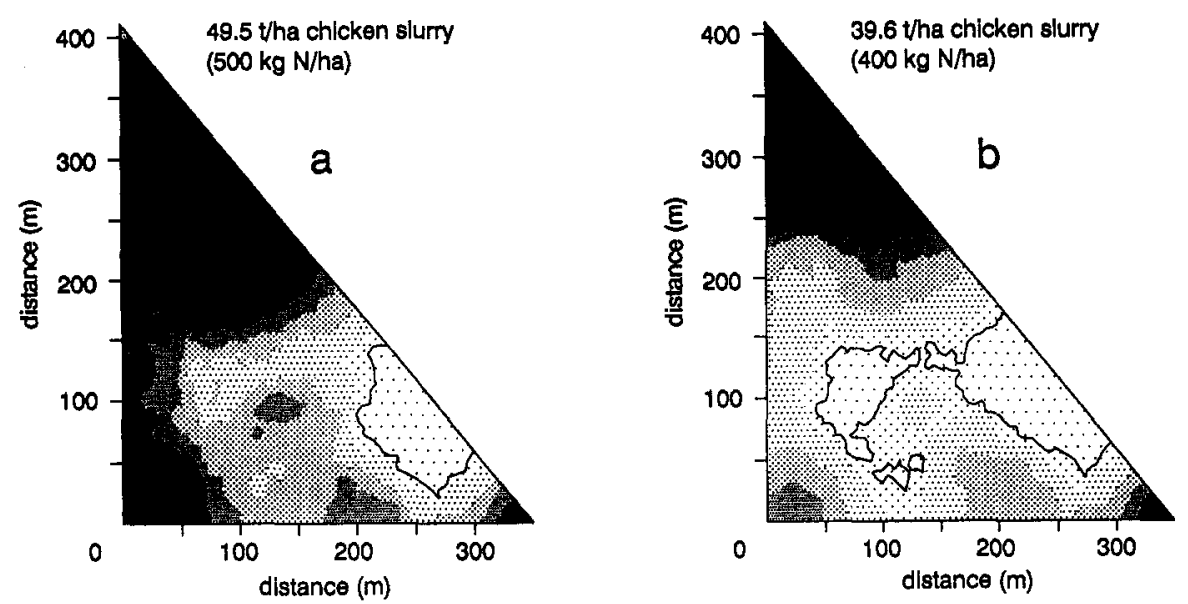

101
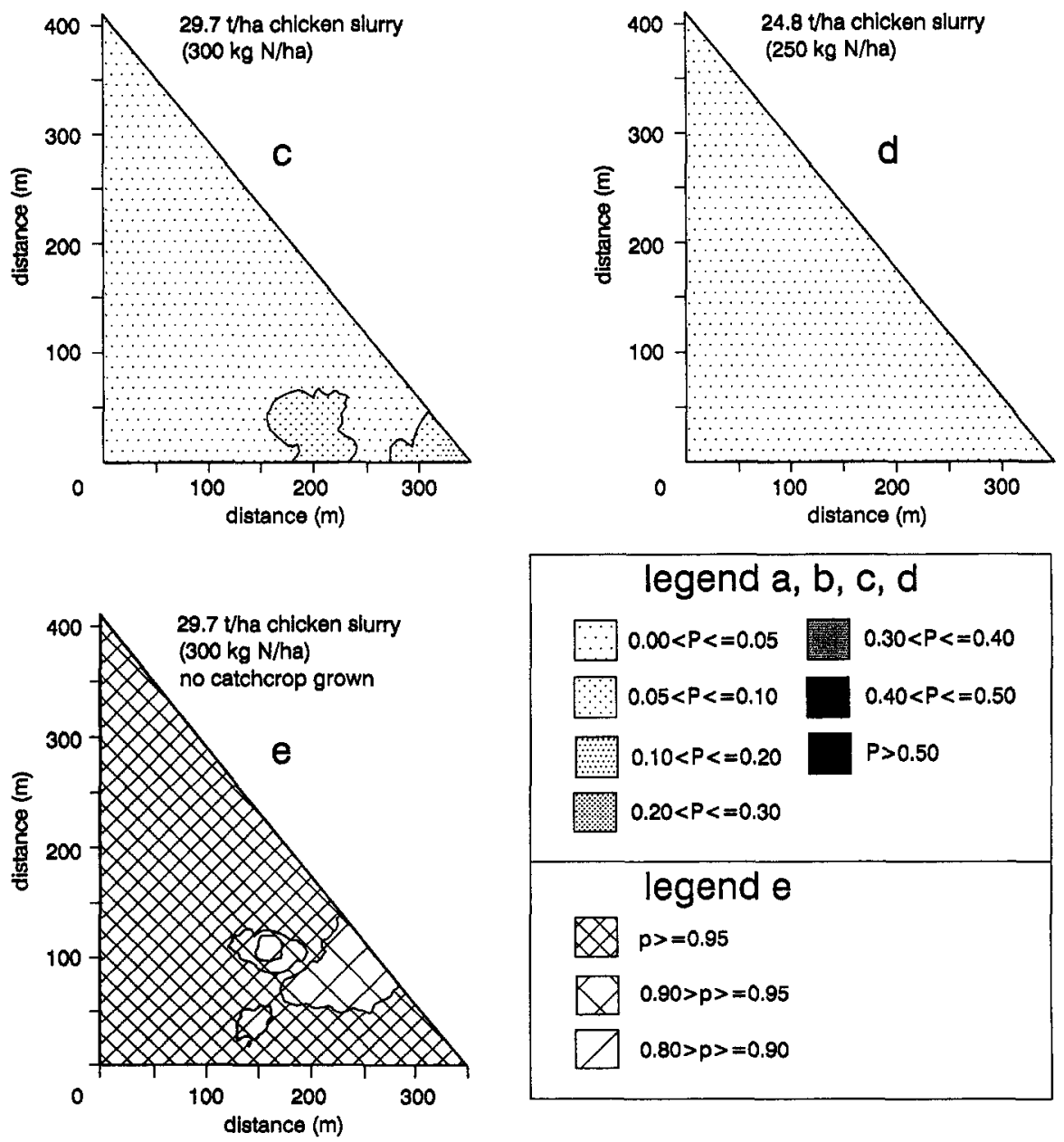

Fig. 5. Maps of the probability $(P)$ that leaching exceeds $50 \mathrm{mg} \mathrm{NO}-\mathrm{N} / \mathrm{dm}^{3}$ at slurry applications from 500-250 kg N/ha when a catchcrop is grown (a to d) or not grown (e). 


\section{TABLE 3}

Comparison of field specific and soil specific maximum amounts of slurry not leading to exceedance of the leaching criterium. Soil codes refer to Fig. 2

\begin{tabular}{|c|c|c|c|c|c|}
\hline \multirow{3}{*}{$\begin{array}{l}\text { Soil } \\
\text { unit }\end{array}$} & \multirow{3}{*}{$\begin{array}{l}\text { Area } \\
(\%)\end{array}$} & \multicolumn{4}{|c|}{ Application of slurry } \\
\hline & & \multicolumn{2}{|l|}{ soil specific } & \multicolumn{2}{|l|}{ field specific } \\
\hline & & $\begin{array}{l}\text { level } \\
\text { (t slurry/ha) }\end{array}$ & $\begin{array}{l}\text { yield } \\
(\mathrm{t} \mathrm{dm} / \mathrm{ha})\end{array}$ & $\begin{array}{l}\text { level } \\
\text { (t slurry/ha) }\end{array}$ & $\begin{array}{l}\text { yield } \\
\text { ( } \mathrm{tdm} / \mathrm{ha})\end{array}$ \\
\hline A & 23 & 29.7 & 9.4 & 24.8 & 9.1 \\
\hline B1 & 19 & 39.6 & 9.5 & 24.8 & 8.4 \\
\hline B2 & 8 & 39.6 & 7.3 & 24.8 & 6.3 \\
\hline \multirow[t]{2}{*}{$\mathrm{C}$} & 50 & 24.8 & 9.2 & 24.8 & 9.2 \\
\hline & & tonnage & tonnage & tonnage & tonnage \\
\hline Field & & 215.1 & 65.7 & 177.9 & 63.1 \\
\hline
\end{tabular}

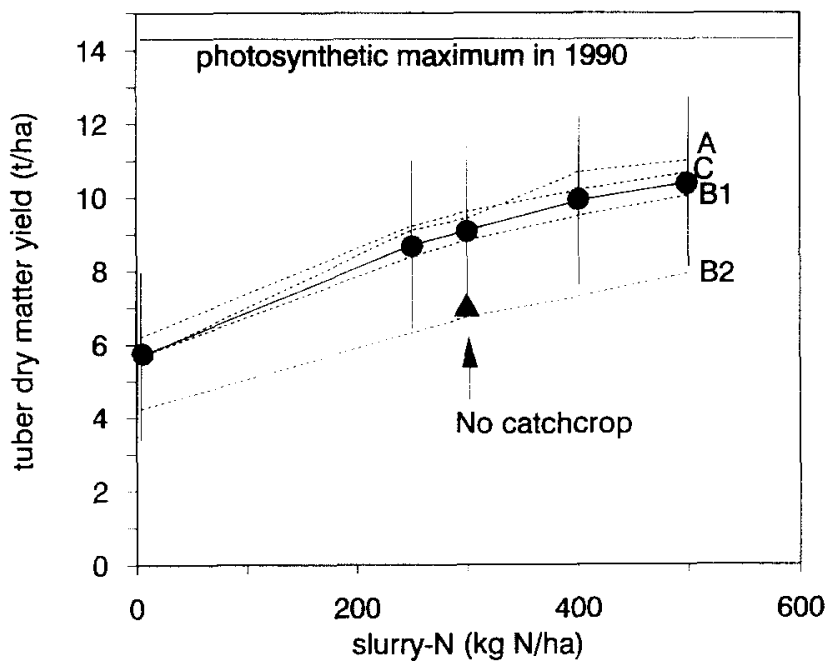

Fig. 6. Simulated average and soil specific crop response in 1990 to slurry additions in 1989. A, B1, B2 and C refer to soil units (see Fig. 2); solid lines connects average crop response and zones of 1 standard deviation, dashed lines connect soil-specific responses; dots represent average yields; triangle represents average yield for scenario without a catchcrop.

and plant nitrogen uptake occured when slurry was incorporated into the upper $15 \mathrm{~cm}$ in the soil. In case of surface application, nitrate leaching was slightly lower, but this was more than compensated for by the far higher ammonia volatilization. Both crop production and total nitrogen losses to the environment were more favourable in case of incorporation. For these reasons, further scenario analyses considered slurry applications to be incorporated into the soil. 
Simulated effects on nitrate leaching of slurry additions of $500,400,300$ and $250 \mathrm{~kg} \mathrm{~N} / \mathrm{ha}$ are presented as leaching probability maps in Fig. 5. The criterion that "nowhere in the field the probability of exceeding the cutoffleaching concentration may be greater than $5 \%$ " was met with a slurry addition equalling $250 \mathrm{~kg} \mathrm{~N} / \mathrm{ha}$. The important role of the catchcrop in minimizing nitrate leaching concentrations is obvious from the leaching probability map at $300 \mathrm{~kg} \mathrm{~N} /$ ha slurry addition when no catchcrop is grown (Fig. 5e). Comparing leaching probability maps with the soil map, shows that soil units $A$ and $C$ (Fig. 2) are more sensitive to nitrate leaching than soil units B1 and B2. This result was used to determine soil specific slurry application rates. If the slurry gift would be $300 \mathrm{~kg} \mathrm{~N} / \mathrm{ha}$ for soil A, $400 \mathrm{~kg} \mathrm{~N} / \mathrm{ha}$ for soils B1 and $\mathrm{B} 2$, and 250 for soil $\mathrm{C}$, the leaching criterion would still be met, but $21 \%$ more slurry could be applied to the whole field, and the crop yield for the whole field would increase by $4 \%$ (Table 3 ).

Simulated potato yield response to the various slurry gifts and its spatial variation is presented in Fig. 6 . Slurry additions higher than $250 \mathrm{~kg} \mathrm{~N} /$ ha still showed a positive effect on potato yields, but the differences are not large. The photosynthetic maximum was not reached by far, indicating that something else than nitrogen deficiency depressed crop yields. This cause has been identified as moisture stress (Finke, 1992), and explained why the variability in crop yields (Fig. 6) was not decreasing when slurry-N additions increased. Different soil units showed a different response to slurry-N (Fig. 6). When no catchcrop would be grown, not only would leaching drastically increase, but also crop yields would be significantly less (Fig. 6).

\section{Inorganic nitrogen fertilizer scenarios}

Simulated nitrate leaching concentrations did not exceed the criterion based on the current threshold concentration of $50 \mathrm{mg}$ nitrate- $\mathrm{N} / \mathrm{dm}^{3}$. However, the pursued threshold concentration of $25 \mathrm{mg}$ nitrate- $\mathrm{N} / \mathrm{dm}^{3}$ was exceeded in case of scenario variants 0 and 6 (Table 4 ).

Variants 0 and 3 were identical in terms of the way the fertilizer level was calculated (see Table 1 ). The strong difference in probability of leaching between variants 0 and 3 must therefore be attributed to a lagged effect of high fertilizer levels in the past, which created a pool of (organically bound) nitrogen that was emptied largely during the simulation period of variant 0 . The high input scenario variant 6 resulted in exceedance of the threshold probability of $5 \%$ in part of the field, which indicates that this scenario will not reduce leaching to the pursued level. Scenario variants 1 to 5 would not violate the threshold probability during the simulation period.

In Fig. 7, the average and soil-specific response of potato yield to the fertilizing scenario is presented. Scenario variant 0 resulted in clearly higher average yields than variant 3 , because more inorganic nitrogen is mineralized dur- 
TABLE 4

Percentage of the area not satisfying quality criteria based on the probability that a leaching concentration greater than $25 \mathrm{mg}$ nitrate- $\mathrm{N} / \mathrm{dm}^{3}$ is exceeded. Variants refer to Table 1

\begin{tabular}{lccccc}
\hline Variant & \multicolumn{2}{l}{ Probability greater than } & & \\
\cline { 2 - 6 } & 0.50 & 0.25 & 0.10 & 0.05 & 0.025 \\
\hline 0 & 66.8 & 94.1 & 99.0 & 99.5 & 99.8 \\
1 & 0 & 0 & 0 & 0 & 0 \\
2 & 0 & 0 & 0 & 0 & 0 \\
3 & 0 & 0 & 0 & 0 & 0 \\
4 & 0 & 0 & 0 & 0 & 0 \\
5 & 0 & 0 & 0 & 0 & 0 \\
6 & 0 & 0 & 0 & 1.4 & 15.5 \\
\hline
\end{tabular}

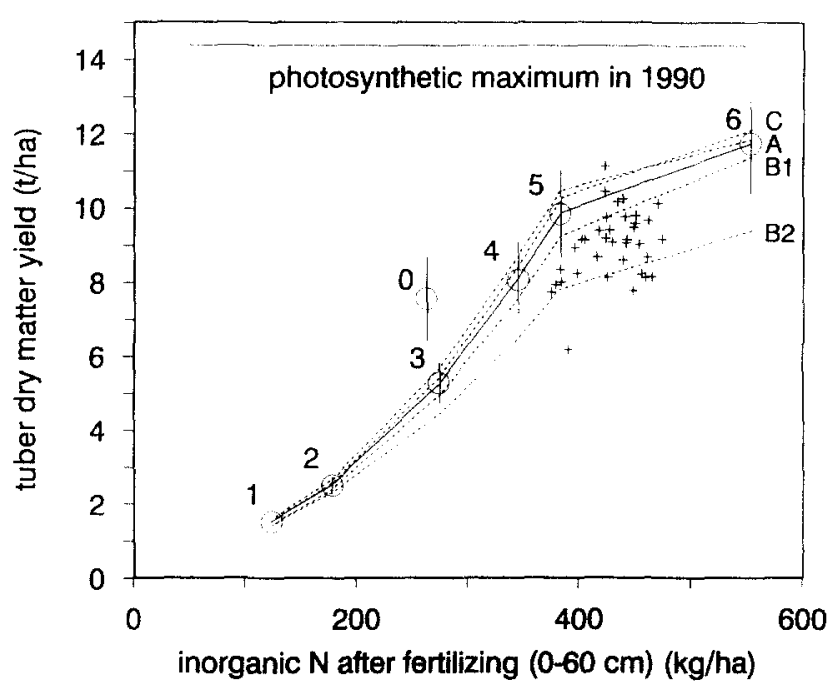

Fig. 7. Simulated average and soil-specific crop response to fertilizer levels in 1990. A, B1, B2 and $C$ refer to soil units (see Fig. 2); 0 to 6 refer to fertilizer scenarios (see Table 1); solid line connects average crop-response and zones of 1 standard deviation, dashed lines connect soilspecific responses; plusses represent field measurements in 1990.

ing the growing season. The vertical bars in Fig. 7 indicate that crop yield becomes more variable when fertilizer gifts are higher. This must be attributed to the increasing importance of water-availability as a factor that is stressing crop growth. Soil units B2 and, to a lesser extent, B1 show a clearly weaker response to $\mathrm{N}$ availability, because capillary rise in these soils is limited by a thick clay loam layer, causing the actual transpiration to be lower than the potential transpiration.

In case of scenario variant 6 , the pursued leaching concentration of $25 \mathrm{mg}$ / $\mathrm{dm}^{3}$ was exceeded only in soil unit $\mathrm{C}$. Soil unit specific fertilizing according 


\section{TABLE 5}

Variability (coefficients of variation) of simulated yields, nitrate leaching concentrations and residual inorganic nitrogen after 17 months for plot-specific, soil-specific and field-specific fertilizing. Variants refer to Table 1

\begin{tabular}{|c|c|c|c|c|}
\hline \multirow[t]{2}{*}{ Variant } & \multirow[t]{2}{*}{ Variable } & \multicolumn{3}{|c|}{ Spatial resolution of application } \\
\hline & & $\begin{array}{l}\text { plot } \\
\text { CV }(\%)\end{array}$ & $\begin{array}{l}\text { soil } \\
\text { CV }(\%)\end{array}$ & $\begin{array}{l}\text { field } \\
\text { CV }(\%)\end{array}$ \\
\hline 0 & yield & 14.97 & 14.84 & 14.80 \\
\hline 1 & & 6.41 & 6.43 & 6.47 \\
\hline 2 & & 7.58 & 7.55 & 7.62 \\
\hline 3 & & 10.28 & 9.87 & 9.88 \\
\hline 0 & leaching conc. & 20.65 & 20.65 & 20.65 \\
\hline 1 & & 68.90 & 68.90 & 68.90 \\
\hline 2 & & 59.61 & 59.61 & 59.61 \\
\hline 3 & & 38.63 & 38.63 & 38.63 \\
\hline 0 & residual $\mathbf{N}$ & 6.36 & 6.47 & 6.49 \\
\hline 1 & & 3.58 & 3.63 & 3.63 \\
\hline 2 & & 3.95 & 4.02 & 4.02 \\
\hline 3 & & 5.37 & 5.50 & 5.51 \\
\hline
\end{tabular}

to scenario variant 5 for soil $\mathrm{C}$ and according to variant 6 for units $\mathrm{A}, \mathrm{B} 1$ and B2 would satisfy the leaching criterion. This would result in a field yield of 77.0 ton dry matter whereas field-specific fertilizing according to scenario variant 5 would produce 70.7 ton dry matter. Soil specific fertilizing would thus increase field yields by $9 \%$.

A comparison of some simulation results of point-specific, soil unit specific and field-specific fertilizing for variants 0 to 3 (Table 1 ) is made in Table 5.

Differences between treatments are small or absent. The variability of yields would decrease when fertilization would change from field-specific to soilspecific only when fertilizer levels are low (variants 1 and 2). Further differences between soil- and field-specific fertilizing are negligible. The residual amount of inorganic nitrogen after 17 months is consequently more variable for field-specific fertilizer applications than for point-specific applications. This indicates that, on the long run, plot-specific fertilizing may produce a less variable nitrogen status than field-specific fertilizing.

As a result, it is concluded that fertilizing by soil instead of fertilizing by field would not have a significant effect on crop yields when it pursues a homogeneous nitrogen distribution over the field. When fertilizer levels are obtained from soil specific response characterictics (Fig. 7), soil specific fertilizing may result in raising average yields.

\section{CONCLUSIONS}

(1) Scenario analyses by simulation modelling form an operational tool to evaluate the effect of fertilizer management. When simulation model param- 
eters reflect soil spatial variability, variability of simulation results can be used to map the probability that critical levels are exceeded. A promising tool to determine these probabilities is the method of disjunctive kriging.

(2) Both leaching response and crop yield response to the slurry application level differ by soil unit. Soil specific optimal slurry treatments (optimal in the sense that leaching criterion is not exceeded) results in higher total applications and higher yields than field specific optimal treatments.

(3) Soil specific nitrogen fertilizer advices did not result in different leaching or crop yields when compared to field- or point-specific advices. Soil specific crop response curves show that the response to inorganic nitrogen differs by soil type.

(4) Spatial variability of yields increased when nitrogen levels increased. This is caused by an increasing variability of the transpiration deficit due to differences in foliar growth as governed by water availability.

\section{ACKNOWLEDGEMENTS}

Financial support by EC-project EV4V*0098-NL "Nitrate in Soils" is gratefully acknowledged. Thanks are due to J. Bouma for critically reading the manuscript.

\section{REFERENCES}

Abramowitz, M. and Stegun, A., 1965. Handbook of Mathematical Functions. Dover, New York. Belmans C., Wesseling, J.G. and Feddes, R.A., 1983. Simulation model of the water balance of a cropped soil: SWATRE. J. Hydrol., 63(3/4): 271-286.

Feddes, R.A., De Graaf, M., Bouma, J. and Van Loon, C.D., 1988. Simulation of water use and production of potatoes as affected by soil compaction. Potato Res., 31: 225-239.

Finke, P.A., 1991. Soil survey to obtain basic simulation data for a heterogeneous field with stratified marine soils. In: Nitrate in Soils. Commission of the European Communities Soil and Groundwater Research Report II (EUR 13501 EN), Luxemburg.

Finke, P.A., 1992. Integration of remote sensing data in the simulation of spatiallyt variable yield of potatoes. Soil Technol., 5: 257-270.

Finke, P.A. and Bosma, W.F.P., 1993. Obtaining basic simulation data for a heterogeneous field with stratified marine soils. Hydrol. Process., 7(2): 7: 63-75.

Finke, P.A., Bouma, J. and Stein, A., 1992. Measuring field variability of disturbed soils for simulation purposes. Soil Sci. Soc. Am. J,,: 187-192.

Greenwood, D.J., Neeteson, J.J. and Draycott, A., 1985. Response of potatoes to N fertilizer: quantitative relations for components of growth. Plant Soil, 85: 163-183.

Hutson, J.L. and Wagenet, R.J., 1991. Simulating nitrogen dynamics in soils using a deterministic model. Soil Use Manage., 7(2): 74-78.

Johnsson, H., Bergstrom, L., Jansson, P.-E. and Paustian, K., 1987. Simulated nitrogen dynamics and losses in a layered agricultural soil. Agric. Ecosyst. Environ., 18: 333-356.

Kim, Y.C., Myers, D.E. and Knudsen, H.P., 1977. Advanced geostatistics in ore reserve estimation and mine planning practioner's guide. Report to the U.S. Energy Research and Development Administration, subcontract No. 76-003-E, Phase II. 
Neeteson, J.J., Greenwood, D.J. and Draycott, A., 1987. A dynamic model to predict yield and optimum nitrogen fertilizer application rate for potatoes. Proceedings 262 . The Fertiliser Society, London, $31 \mathrm{pp}$.

Soil Survey Staff, 1975. Soil Taxonomy: A Basic System of Soil Classification for Making and Interpretating Soil Surveys. USDA-SCS Agric. Handb. 436. U.S. Gov. Print. Office, Washington, DC.

Van Genuchten, M.Th,, 1980. A closed form equation for predicting the hydraulic conductivity of unsaturated soils. Soil Sci. Soc. Am. J., 44: 892-898.

Wagenet, R.J., 1983. Principles of salt movement in soils. In: D.W. Nelson et al. (Editors), Chemical Mobility and Reactivity in Soil Systems. Spec. Publ. 11, Am. Soc. of Agronomy, Madison, WI, pp. 123-140.

Webster, R., 1977. Quantitative and Numerical Methods in Soil Classification and Survey. Clarendon Press, Oxford.

Webster, R. and Oliver, M.A., 1989. Optimal interpolation and isarithmic mapping of soil properties. VI. Disjunctive kriging and mapping the conditional probability. J. Soil Sci., 40: 497512.

Wösten, J.H.M., Bannink, M.H., De Gruijter, J.J. and Bouma. J., 1986. A procedure to identify different groups of hydraulic-conductivity and moisture-retention curves for soil horizons. J. Hydrol., 86: 133-145.

Wösten, J.H.M., Schuren, C.H.E.J., Bouma, J. and Stein, A., 1990. Functional sensitivity analysis of four methods to generate soil hydraulic functions. Soil Sci. Soc. Am. J., 54: 832-836.

Yates, S.R., Warrick, A.W. and Myers, D.E., 1986. Disjunctive kriging. 1. Overview of estimation and conditional probability. Water Resour. Res., 22(5): 615-621. 